\title{
MANIFESTACIONES RADIOGRAFICAS DE LA TUBERCULOSIS PULMONAR
}

\author{
Drs. Gonzalo Miranda $G^{(1)}$, Juan Carlos Díaz $P^{(1)}$, Patricia Arancibia $H^{(1)}$, Monica Antolini $T^{(1)}$, \\ Int. Carolina Díaz $G^{(2)}$, Int. Alvaro Vidal $F^{(2)}$.
}

1. Hospital Clínico de la Universidad de Chile. 2. Hospital San Juan de Dios.

\begin{abstract}
Tuberculosis is a pathology that has accompanied humanity since ancient times and regardless the existence of antibiotics for more than a century and that tuberculosis is a preventable and treatable disease, eradication is a goal not yet achievable. In Chile 40 to 70 cases are diagnosed every week which means physicians are constantly faced to this disease. The diagnosis is suspected based on typical respiratory symptoms and chest radiographs is the first imagenological approach. Several radiographical patterns, with interstitial and parenquimatous involvement are main features of this disorder. These manifestations are related to the patient's age, immunological status, previous exposure and disease stage. Different radiological patterns are shown from patients admitted in our hospital at the first semester of this year.

Key words: Pulmonary tuberculosis, Radiological patterns, $X$-Ray thorax.
\end{abstract}

Resumen: La tuberculosis (TBC) es una patología que ha acompañado al hombre desde los comienzos de la historia, y a pesar de que hace más de medio siglo se cuenta con antibióticos eficaces y se puede considerar una enfermedad prevenible, tratable $y$ erradicable, esta meta está lejos de ser alcanzada. En Chile se diagnostican semanalmente entre 4070 casos, lo que significa que el médico está constantemente enfrentado este cuadro. Por lo general, el diagnóstico se sospecha sobre la base de la sintomatología y antecedentes epidemiológicos, siendo la radiografía de tórax el primer examen de aproximación diagnóstica. Diversos patrones radiológicos, con compromiso parenquimatoso y/o intersticial, son característicos y las manifestaciones

\footnotetext{
Miranda G. y cols. Manifestaciones radiográficas de la tuberculosis pulmonar. Rev Chil Radiol 2004; 10: 178-182. Correspondencia: Dr. Gonzalo Miranda G. Hospital Clínico de la Universidad de Chile. Santos Dumont 999. Independencia. Teléfono: 6788412-7642495-094486006; Fax: 7354849

Email:gomiranda2000@yahoo.com
}

son dependientes de la edad del paciente, de su estado inmunológico, de la exposición previa y de sí estamos frente a un cuadro primario o posprimario. Presentamos distintos patrones radiológicos de la TBC pulmonar, en pacientes atendidos durante el primer semestre de este año en el Hospital Clínico de la Universidad de Chile y en el Hospital San Juan de Dios.

Palabras claves: Patrones radiográficos, Radiografía tórax, Tuberculosis pulmonar.

\section{Introducción}

La asociación entre tuberculosis (TBC) y el hombre precede a la historia escrita, como lo prueba el descubrimiento de sus lesiones en osamentas muy antiguas. Entre ambas especies hay un particular modo de coexistencia, la cual generalmente no significa enfermedad humana, sino la muerte de los bacilos. A pesar de que ya en el año 1882 Robert Koch descubrió al agente causal de esta enfermedad (Mycobacterium tuberculosis), que hace más de 50 años se cuenta con antibióticos eficaces en la lucha contra la TBC y que tanto los conocimientos médicos como tecnológicos son suficientes para considerarla como una enfermedad prevenible, tratable y erradicable $^{(1)}$, esta meta está lejos de ser alcanzada. Durante estos últimos años diferentes países han presentado un quiebre en la tendencia decreciente de su prevalencia, lo que se explicaría, en parte, por la aparición y diseminación del VIH y por otra, a la relajación en los programas de salud pública sobretodo en países desarrollados, en los que la enfermedad tienen una baja prevalencia. Lo anterior determinó que en el año 1993 la Organización Mundial de la Salud declarase a la TBC como una emergencia global(2).

En Chile, la forma pulmonar aún es una causa importante de morbimortalidad. Actualmente, se diagnostican entre 40 a 70 nuevos casos semanalmente ${ }^{(3)}$. Los médicos, por lo tanto, están permanentemente enfrentados a esta enfermedad, ya sea como caso individual o como problema de salud pública. 


\section{Objetivos}

Realzar los distintos patrones radiográficos de la TBC pulmonar, tanto en pacientes inmunocompetentes como inmunosuprimidos y ante los cuales debe sospecharse esta probalidad de diagnóstico.

\section{Materiales y métodos}

Se revisaron las fichas clínicas de pacientes con diagnóstico de TBC pulmonar confirmada, ya sea mediante baciloscopía y/o cultivo positivo, hospitalizados durante el primer semestre de este año en el Hospital Clínico de la Universidad de Chile y en el Hospital San Juan de Dios. Se analizaron un total de 14 pacientes, 9 hombres y 5 mujeres, cuyas edades fluctuaron entre los 23 y 68 años. Tres de estos pacientes eran VIH positivos. Se procedió a analizar las radiografías de tórax antero-posterior y lateral, obtenidas al momento del ingreso. Los patrones radiográficos obtenidos fueron condensaciones en 8 pacientes, 5 de las cuales mostraban áreas sugerentes de excavación. Tres pacientes se presentaron con adenopatías mediastínicas, 2 con patrón miliar y un caso con derrame pleural e imágenes parenquimatosas apicales. Los patrones radiológicos encontrados en los tres pacientes con VIH positivo fueron adenopatías mediastínicas, patrón miliar y condensación con área de excavación. Se realizó revisión tanto de literatura chilena como internacional publicada sobre el tema, en revistas especializadas y bases de datos (Medline, Cochrane, entre otras).

\section{Manifestaciones Clínicas}

La clínica de la TBC pulmonar es a menudo inespecífica, siendo un $5 \%$ de los casos asintomático(4). Dentro de las manifestaciones sistémicas se incluyen febrículas, anorexia, sudoración nocturna y baja de peso persistente, además de los síntomas respiratorios como tos, expectoración (mucopurulenta/hemoptoica) o franca hemoptisis ${ }^{(5,6)}$.

Por otro lado, las características de la TBC en pacientes infectados por VIH son dependientes de la severidad de la inmunosupresión. Pacientes con sistema inmune celular relativamente intacto presentan síntomas similares a los de pacientes no infectados, permaneciendo generalmente la infección localizada a nivel pulmonar. Sin embargo, si la infección por VIH está en una etapa avanzada (CD4 $<200 / \mathrm{mm}^{3}$ ), la TBC pulmonar puede acompañarse de compromiso extrapulmonar, presentándose frecuentemente como linfoadenitis y diseminación $\operatorname{miliar}^{(7,8)}$.

\section{Presentación radiológica}

La radiografía de tórax es el primer método de aproximación diagnóstica y si es normal tiene un alto valor predictivo negativo cuando se sospecha TBC pulmonar activa, siendo la frecuencia de falsos negativos de aproximadamente $1 \%{ }^{(4)}$, sin embargo, este valor se incrementa a un $7-15 \%$ en pacientes seropositivos para $\mathrm{VIH}^{(9)}$.

Las manifestaciones radiológicas son dependientes de factores del huésped, incluyendo la exposición previa, la edad y su estado inmune; y pueden ser divididas en TBC primaria y posprimaria, siendo en determinadas oportunidades, difícil la diferenciación entre ambas ${ }^{(5)}$.

a) TBC primaria: Su sello es la presencia de linfoadenopatías, las cuales son comunes en niños y en adultos con VIH (Figura 1). La naturaleza de las opacidades parenquimatosas puede ser tanto del espacio aéreo como del intersticio, siendo la consolidación del espacio aéreo el patrón radiológico más común (Figura 2), acompañado en ocasiones de excavaciones ${ }^{(5)}$. Por otro lado, el patrón intersticial más frecuente de la enfermedad primaria es la TBC miliar (Figura 3)(4-6,10). Otras manifestaciones incluyen: 1) Enfermedad traqueobronquial manifestada como atelectasias o hiperinsuflación secundaria, causadas por compresión extrínseca de las vías respiratorias por los ganglios linfáticos hipertróficos. 2) Enfermedad pleural, manifestándose por derrame de tamaño variable, pudiendo comprometer incluso un hemitórax completo (Figura 4). En muchos casos no se puede visualizar una anormalidad parenquimatosa con las radiografías simples, pero el reconocimiento de un derrame pleural es importante con el objetivo de realizar otros estudios diagnósticos ${ }^{(5)}$.

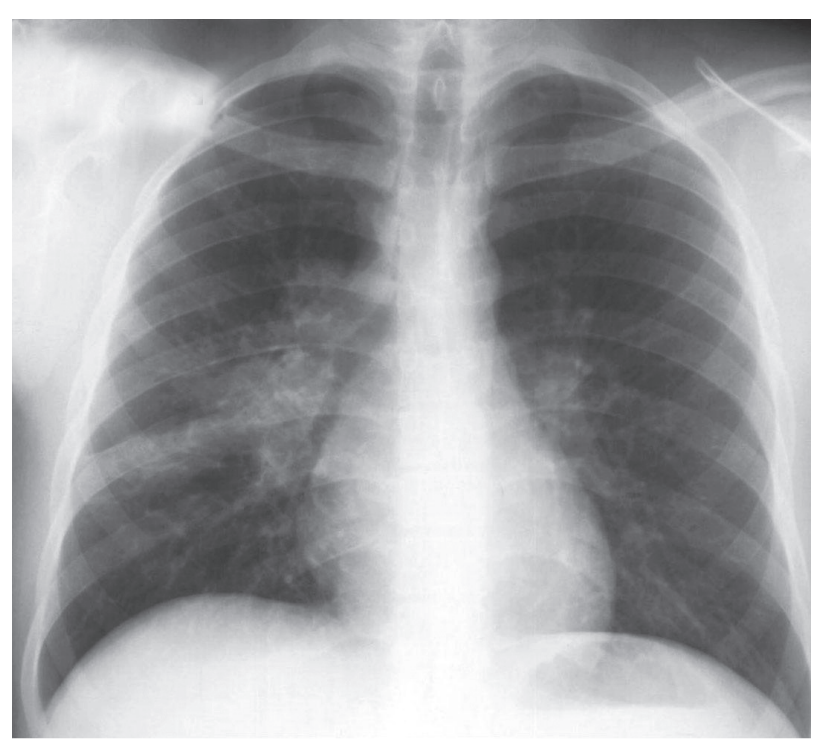

Figura 1. Adenopatías a nivel del hilio pulmonar derecho, asociado a imágenes parenquimatosas, manifestación de tuberculosis primaria. El diagnostico diferencial debe considerar linfoma y cáncer pulmonar.

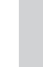




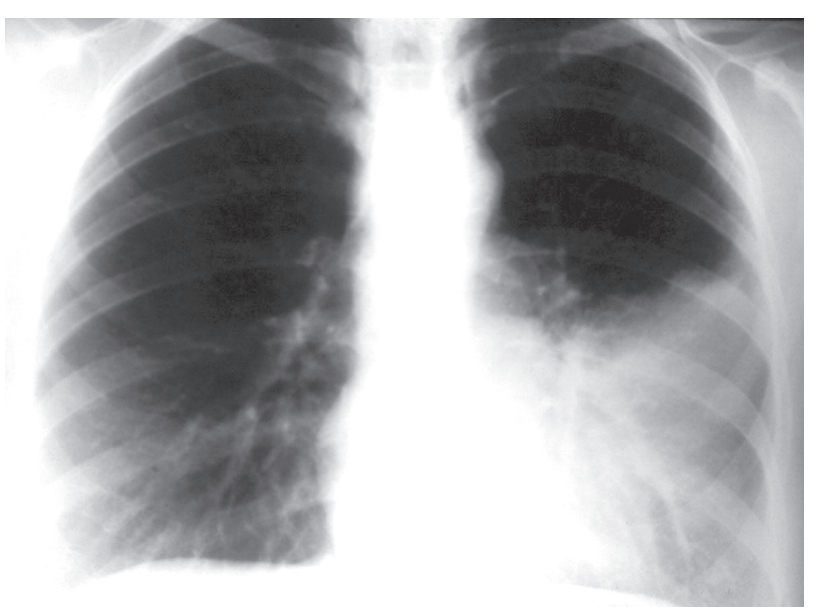

Figura 2. Condensación basal izquierda con mala respuesta a tratamiento como neumonía bacteriana adquirida en la comunidad. Las baciloscopías demostraron tuberculosis.

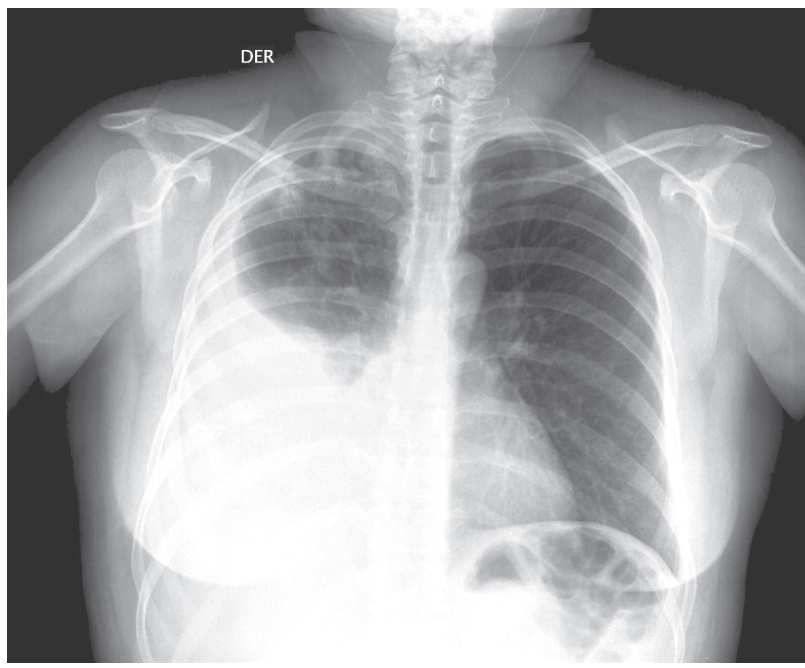

Figura 4. Derrame pleural basal e imágenes parenquimatosas apicales derechas. El estudio del líquido pleural demostró tuberculosis. La presencia de un derrame pleural en un paciente joven relativamente asintomático es altamente sugerente de tuberculosis.

b) Tuberculosis post-primaria: Es la forma más común de enfermedad en los adultos y ocurre en individuos que han desarrollado inmunidad mediada por células e hipersensibilidad tardía a M. tuberculosis. En la mayoría de los individuos con infección tuberculosa latente, el sistema inmune puede controlar la infección. Sin embargo, en algunos individuos, el microorganismo puede reactivarse y proliferar, causando TBC post-primaria ${ }^{(11)}$.

Aunque sus manifestaciones radiográficas se superponen con las de la enfermedad primaria, hay varios atributos que las distinguen como lo son; la predilección por los lóbulos superiores, ausencia de linfodenopatías y propensión a la excavación. La

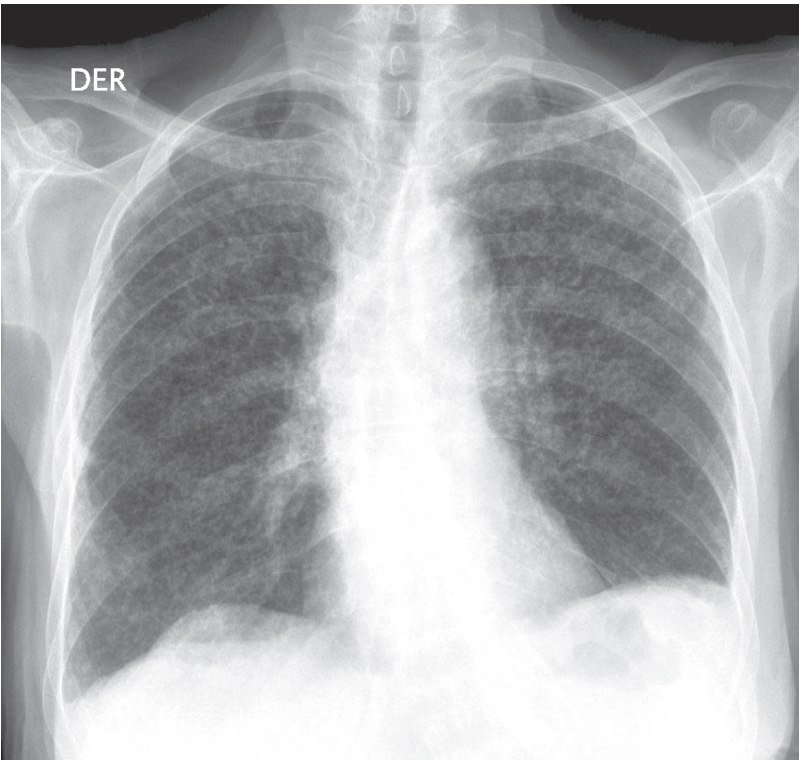

Figura 3. Patrón miliar. Pequeños micromódulos de 1 a 3 $\mathrm{mm}$. distribuidos difusamente en ambos campos pulmonares.

consolidación del espacio aéreo es también el patrón más común de enfermedad (Figura 5, 6). En la mayoría de los casos, hay sin embargo una mezcla de patrones radiográficos como por ejemplo, mezcla de opacidades lineales, reticulares y nodulares. La excavación es también una característica importante de la tuberculosis post-primaria. Las cavernas ocurren como resultado de necrosis caseosa y, usualmente, contienen la mayor concentración de micobacterias que cualquier otra lesión tuberculosa (Figuras 7-9).

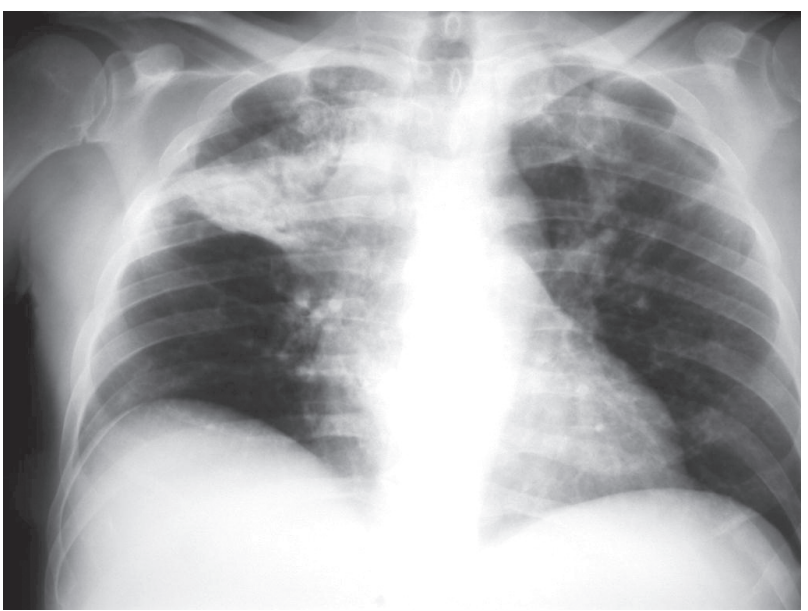

Figura 5. Condensación del lóbulo superior derecho, lugar frecuente de afectación en la tuberculosis post-primaria. 

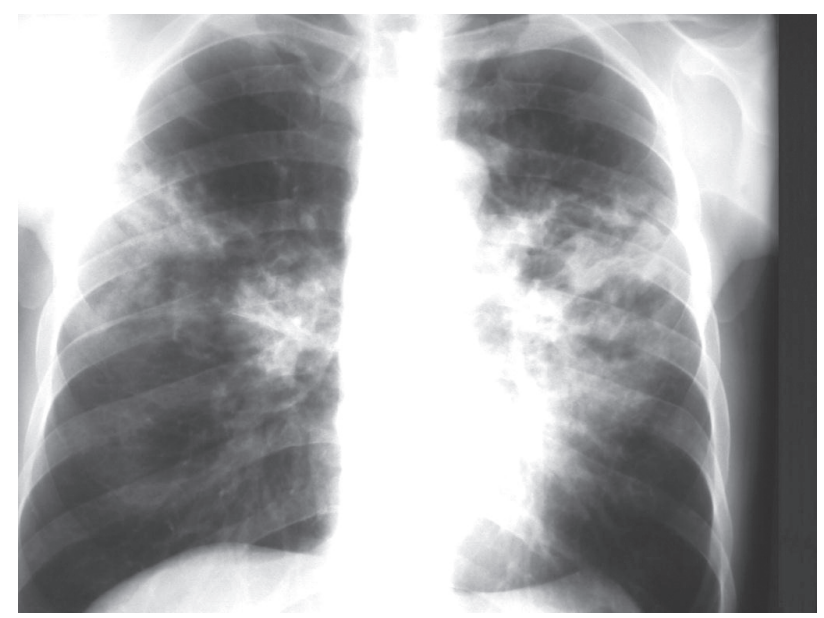

Figura 6. Condensaciones múltiples, con un área sugerente de excavación, como manifestación de tuberculosis.

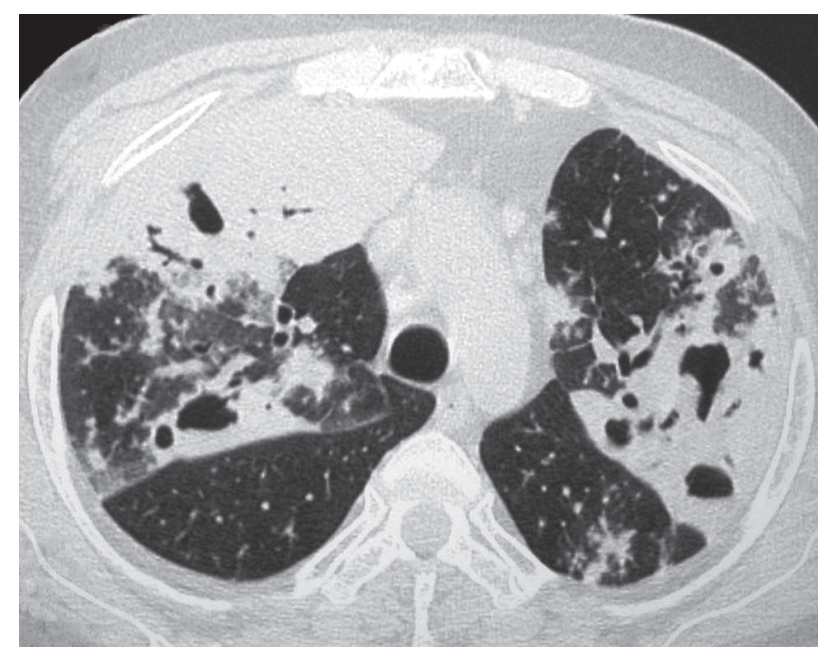

Figura 8. TC de Tórax donde se observan condensaciones con excavaciones, en un paciente con tuberculosis postprimaria.

En pacientes infectados por $\mathrm{VIH}$, cuyo sistema inmune está relativamente intacto, las manifestaciones radiológicas de la TBC representan las observadas en la enfermedad post-primaria, es decir, opacidades en los lóbulos superiores, con o sin excavaciones, siendo la adenopatía torácica poco frecuente. A medida que declina el recuento de linfocitos CD4, los hallazgos radiológicos se asemejan más a los observados en la enfermedad primaria, opacidades en lóbulos inferiores, o compromiso multilobar, siendo las adenopatías torácicas más frecuente, sin embargo, el $10-20 \%$ de ellos presentan una radiografía sin hallazgos patológicos (Figura 10)(7-10).

Diferenciar radiológicamente entre un cuadro activo y otro inactivo es solo posible realizando un seguimiento en el tiempo, de tal forma que si no se

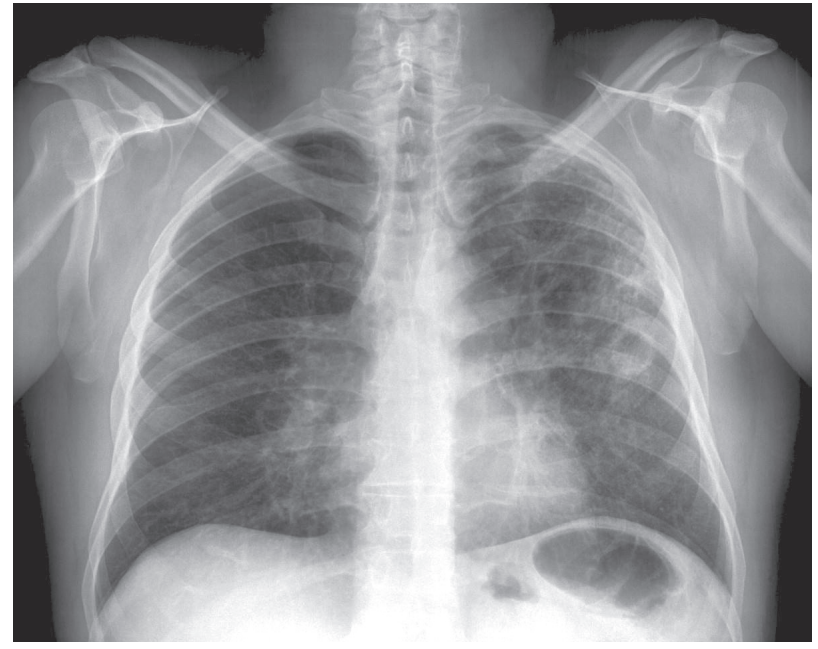

Figura 7. Presencia de un nódulo excavado e imágenes parenquimatosas nodulares por diseminación broncogena.

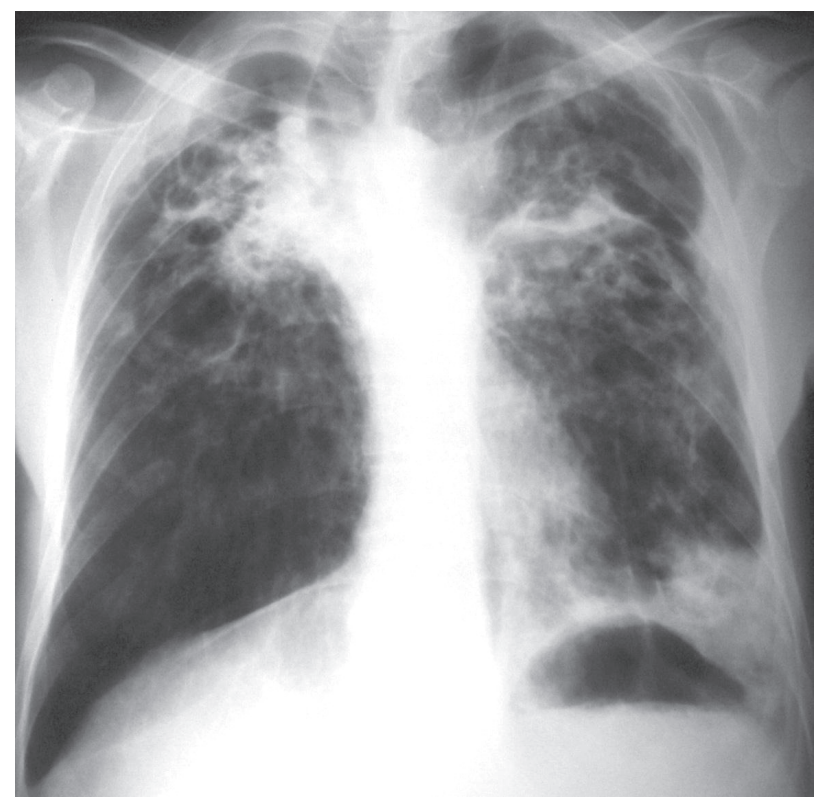

Figura 9. Reducción de volumen del lóbulo superior derecho con tracción del mediastino, tractos fibrosos y excavaciones. El estudio demostró tuberculosis activa.

evidencian cambios tras 4-6 meses de seguimiento, se puede hablar de inactividad(6).

La resolución de las anormalidades radiológicas es lenta. En muchos casos, las opacidades parenquimatosas y la adenopatía torácica empeoran antes de mejorar. Por consiguiente, la radiografía de tórax no es el mejor método de vigilar la respuesta al tratamiento antibiótico. En vez de ello, debe hacerse una evaluación clínica y vigilancia bacteriológica de la terapia, para poder determinar si el paciente está respondiendo. Algunos trabajos muestran signos confiables con el uso de 

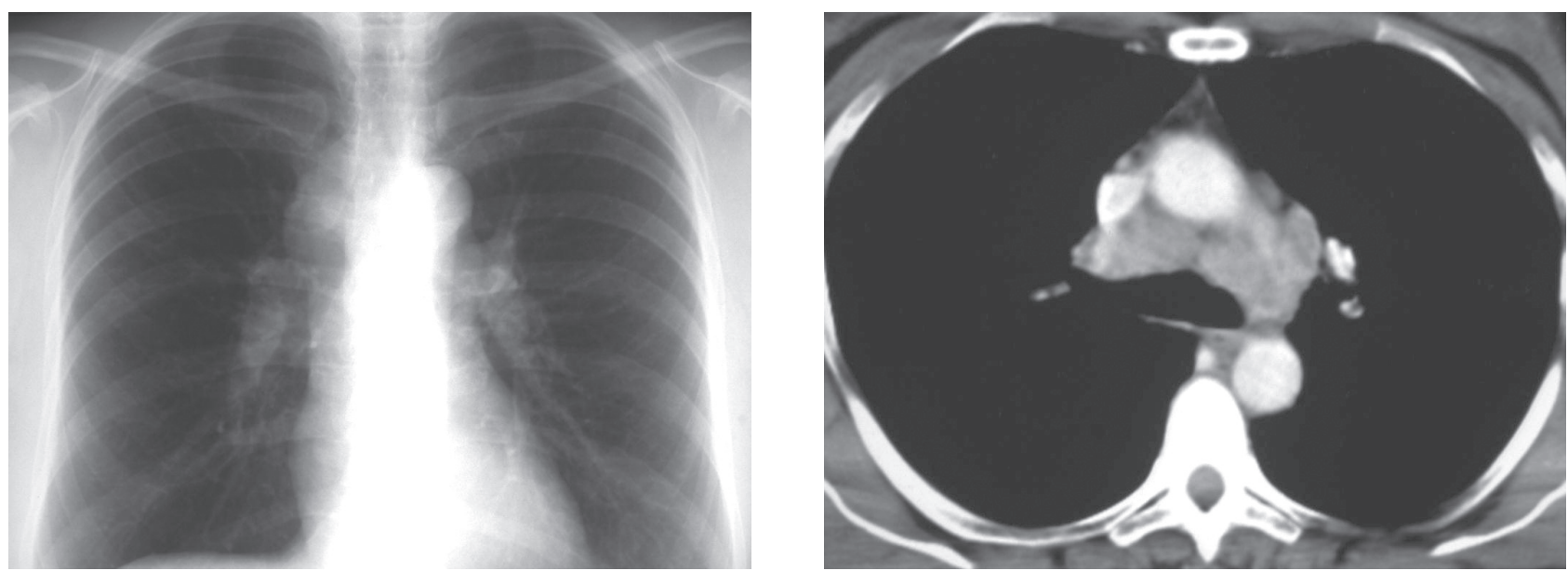

Figura 10 a,b. Paciente VIH positivo. a: Radiografía de tórax que demostró un ensanchamiento mediastinico. b: TC que confirma estos hallazgos mostrando múltiples adenopatías hipodensas. El estudio posterior confirmó una tuberculosis.

TC de tórax para determinar respuesta a tratamiento ${ }^{(10)}$.

\section{Conclusión}

Las manifestaciones radiológicas de la TBC son variadas e inespecíficas. Distintos patrones radiográficos deben hacernos sospecharla, lo que en un determinado contexto clínico nos confirmará el diagnóstico. Con el incremento del número de pacientes seropositivos para $\mathrm{VIH}$ e inmigrantes, la frecuencia de este cuadro en nuestro medio se ha incrementado, por lo que debemos conocer las diferentes presentaciones radiológicas y ser capaz de diferenciarlas de otras patologías broncopulmonares.

\section{Bibliografía}

1. Centers for diseases control and prevention. A strategic plan for the elimination of tuberculosis in the United Stated. MMWR Morb Mortal Wkly Rep 1989; 38: 1-21.

2. Raviglione MC, Snider DE Jr, Kochi A. Global epidemiology of tuberculosis: morbidity and mortality of a worldwide epidemic. JAMA 1995; 273: 220-226.

3. Boletín semanal de enfermedades de notificación obligatoria. Año estadístico 2004. Ministerio de Salud de Chile, departamento de estadística e información de salud.

4. Korzeniewska-Kosela M, Krysl J, Muller $\mathrm{N}$ et al. Tuberculosis in young adults and the elderly: a prospective comparison study. Chest 1994; 106: 28-32.

5. Leung AN. Pulmonary tuberculosis: the essentials. Radiology. 1999; 210: 307-322.

6. Bass JR Jr, Farer LS, Hopewell PC et al. Diagnostic standards and classification of tuberculosis. Am Rev Respir Dis 1990; 142: 725-735.

7. Theuer CP, Hopewell PC, Elias D et al. Human immunodeficiency virus infection in tuberculosis patients. J Infect Dis 1990; 162: 8-12.

8. Barnes PF, Bloch AB, Davidson PT, Snider DE Jr. Tuberculosis in patients with human immunodeficiency virus infection. N Engl J Med 1991; 324: 1644-1650.

9. Leung AN, Brauner MW, Gamsu G, et al. Pulmonary tuberculosis: comparison of CT findings in HIVseropositive and HIVseronegative patients. Radiology 1996; 198: 687-691.

10. Young H, Song KS, Mo Goo F, et al. Thoracic Sequelae and Complications of Tuberculosis. Radiographics 2001; 21: 839-860.

11. Jones BE, Ryu R, Yang Z, et al. Chest radiographic findings in patients with tuberculosis with recent or remote infection. Am J Respir Crit Care Med 1997; 156: $1270-1273$. 